\title{
Molecular Pathogenesis of Hepatocellular Carcinoma: Altering Transforming Growth Factor- $\beta$ Signaling in Hepatocarcinogenesis
}

\author{
Ken Yamazaki Yohei Masugi Michiie Sakamoto \\ Department of Pathology, School of Medicine, Keio University, Tokyo, Japan
}

\section{Key Words}

Hepatocellular carcinoma • Multistep carcinogenesis • TGF- $\beta$ signaling • Microenvironment $\cdot$ Tumor-stromal interaction $\cdot$ Hepatocyte growth factor

\begin{abstract}
Hepatocellular carcinoma (HCC) occurs subsequent to liver injury, where regenerative hepatocytes develop into a dysplastic nodule and then early HCC, supporting the multistep hepatocarcinogenesis theory. Molecular alterations such as the $p 53$ mutation, p16 gene silencing, and AKT signaling activation are found in the late stage of HCC progression. The overexpression of some marker molecules is observed at the early stage. Transforming growth factor- $\beta$ (TGF- $\beta$ ), a potent inhibitor of cell proliferation, is frequently overexpressed in $\mathrm{HCC}$, although the role of TGF- $\beta$ signaling during $\mathrm{HCC}$ development remains controversial. We previously reported that HCC cells show TGF- $\beta$ receptor-dependent growth inhibition in response to TGF- $\beta$. Also, reduced TGF- $\beta$ receptor II in HCC correlates with intrahepatic metastasis and shorter time-to-recurrence, suggesting a role of TGF- $\beta$ signaling in tumor suppression. In contrast, TGF- $\beta$ overexpression in HCC is known to correlate with malignant potential, suggesting a role in tumor promotion. Enhanced formation of stroma is a feature of advanced HCC, and TGF- $\beta$ also promotes the proliferation of stromal fibroblasts. The microenvironment produced via tumor-stromal interactions may be the key to the modulation of the dual roles of TGF- $\beta$ signaling in HCC progression.

Copyright $\odot 2011$ S. Karger AG, Basel
\end{abstract}

\section{Multistep Hepatocarcinogenesis}

Hepatocellular carcinoma (HCC) is the fourth leading cause of cancer death worldwide [1]. The incidence of HCC differs between geographical regions, and is closely related to the prevalence of chronic infection. Most HCCs develop following chronic liver disease caused by a hepatitis B virus (HBV) and/or hepatitis C virus (HCV) [2] infection. Clinical, radiological, and pathological findings indicate a multistep process in the development of HCC. Dysplastic nodules (DN) are usually found in the liver with chronic inflammation, and will eventually develop into early HCC. The transitional progress from an early to more advanced stage is histologically described as a nodule-in-nodule lesion, where moderately or poorly differentiated tumor grows within a well-differentiated cancer nodule. Advanced HCC often shows intrahepatic metastasis disseminated through portal vein invasion, indicating a poor prognosis. To understand the multistep progression of HCC, molecular alterations can serve as signs for the transition of each step.

\section{Molecular Alterations in HCC}

Gene mutations are a crucial molecular alteration in many cancers, and the $p 53$ gene is the most frequently mutated in HCC. Oda et al. [3] demonstrated mutations of the $p 53$ gene in poorly differentiated tumor components of a nodule-in-nodule type HCC, but no mutation in a well-

\section{KARGER}

Fax +4161306 1234

E-Mail karger@karger.ch

www.karger.com
(C) $2011 \mathrm{~S}$. Karger AG, Basel

$0257-2753 / 11 / 0293-0284 \$ 38.00 / 0$

Accessible online at:

www.karger.com/ddi
Michiie Sakamoto, $\mathrm{MD}, \mathrm{PhD}$

Department of Pathology, School of Medicine, Keio University

35 Shinanomachi, Shinjuku-ku

Tokyo 160-8582 (Japan)

Tel. +81 35363 3762, E-Mail msakamot@ @c.itc.keio.ac.jp 
differentiated tumor component surrounding the former [3]. Nuclear accumulation of mutated p53 is immunohistochemically detected in HCCs, and is correlated with tumor grade and size [4]. These findings indicate that the $p 53$ gene mutation occurs at a later stage in HCC progression.

Epigenetic silencing contributes molecular alterations without gene mutation/deletion in cancer. The p16 $(C D K N 2 A)$ tumor suppressor gene encodes a cyclin-dependent kinase inhibitor that is involved in the cell cycle regulatory pathway. Suppressed p16 expression in HCC is mainly due to hypermethylation of the gene [5]. Loss of p16 protein occurs approximately twice as often in advanced HCCs (40\%) than in early HCCs [5].

Aberrant activation of signal transduction is another molecular alteration in cancer. AKT/PKB phosphorylation has been identified as a significant risk factor for an early recurrence and poor prognosis in HCC [6].

The molecular alterations described above are rare in the early stages of HCC progression, however molecular markers upregulated in the early stages have been reported. Heat-shock protein 70 and adenylate cyclase-associated protein 2 are detected in early HCC, and are highly expressed in advanced HCC $[7,8]$. Since these molecules show a stepwise upregulation with HCC progression, they can serve as useful markers for HCC diagnosis.

Molecular markers detectable in the blood are useful for less invasive diagnoses. Plasma $\alpha$-fetoprotein levels have been an important factor in the diagnosis and prognosis of HCC. Elevated levels of plasma TGF- $\beta$ in HCC patients have been reported [9], but may not be specific for HCC due to upregulation in the inflamed liver. While TGF- $\beta$ is a cell growth inhibitor, its overexpression in HCC correlates with carcinogenesis, progression, and prognosis [10-12]. Indeed, the role of TGF- $\beta$ signaling in HCC is controversial. Recently, we showed that reduced TGF- $\beta$ receptor type II (TGFBR2) expression in HCC correlated with intrahepatic metastasis and shorter time to recurrence [13]. Various roles of TGF- $\beta$ signaling may be implicated in multistep hepatocarcinogenesis.

\section{Canonical TGF- $\beta$ Signaling}

The TGF- $\beta$ superfamily contains molecules with a diverse range of functions in embryogenesis and adult tissue homeostasis. TGF- $\beta$ ligand binds with a heteromeric receptor complex that consists of type I and type II serine/ threonine kinase receptors. Upon ligand-receptor binding, the type I receptor phosphorylates receptor-activated SMAD (R-SMAD) proteins at their C-terminal serines.

TGF- $\beta$ Signaling in Hepatocellular Carcinoma
SMAD is a TGF- $\beta$ signaling transducer with conserved MAD-homology $(\mathrm{MH})$ 1, an intermediate linker, and MH2 regions. The activated R-SMADs, together with SMAD4, translocate into the nucleus and function as a transcription factor complex. One of the target genes of TGF- $\beta$, SMAD7, encodes an inhibitory SMAD that binds to the type I TGF- $\beta$ receptor and competitively blocks the interaction between the TGF- $\beta$ receptor and R-SMAD [14].

The regenerative potential of the liver has been recognized since ancient times and the regenerative capacity of hepatocytes is exploited in the recovery from liver injury. TGF- $\beta$ signaling plays a role in the process of liver regeneration by terminating hepatocyte proliferation [15]. TGF- $\beta$ is also involved in liver fibrosis caused by liver injury by promoting the production of extracellular matrix by fibroblasts. TGF- $\beta$ overexpression is frequently found in HCCs as well as other cancers. Treatment with TGF- $\beta$ results in the growth arrest of HCC cells expressing TGFBR2 [13], indicating that TGF- $\beta$ signaling has a tumor-suppressive role in HCC cells as well as normal hepatocytes. Mechanisms to escape TGF- $\beta$-induced growth arrest may be necessary for HCC progression.

\section{TGF- $\beta$ Signaling in HCC}

Recently we reported that reduced TGFBR2 expression in HCC correlated with intrahepatic metastasis [13]. Approximately $25 \%$ of HCCs showed decreased staining for TGFBR2 compared with adjacent non-cancerous hepatocytes (fig. 1). The TGFBR2 downregulation also correlated with a larger size and higher grade of tumor, and early recurrence time. These findings suggest that TGFBR2 downregulation is a late event in HCC development. TGFBR2-reduced HCC cells exhibited no proliferative response to TGF- $\beta$, whereas the growth of TGFBR2-expressing cells was arrested by TGF- $\beta$ treatment. Thus, the response to TGF- $\beta$ is TGFBR2-dependent. Although TGFBR2 downregulation seems to be a late event in HCC progression, some cases with a small HCC $(\leq 2 \mathrm{~cm})$ showed reduced TGFBR 2 expression $(6 / 60$ small HCCs). Two of these cases demonstrated an early recurrence after surgery [unpubl. data], suggesting that reduced TGFBR 2 expression may be a risk factor for early recurrence, even in patients with a small HCC.

Mutations and deletions of TGF- $\beta$ signaling-related genes are found in some cancers. The SMAD4 gene is lost or mutated in about $50 \%$ of pancreatic carcinomas [16], and the TGFBR2 gene is mutated in hereditary non-polyposis colorectal carcinoma [17]. Alterations of 
Fig. 1. Immunohistochemical detection of TGFBR2 in HCC tissues. Tumor cells with (a) or without (b) staining of TGFBR2. Non-neoplastic hepatocytes and cholangiocytes (arrows) showed positive staining for TGFBR2. The dotted line shows the boundary of the tumor $(\mathrm{T})$.
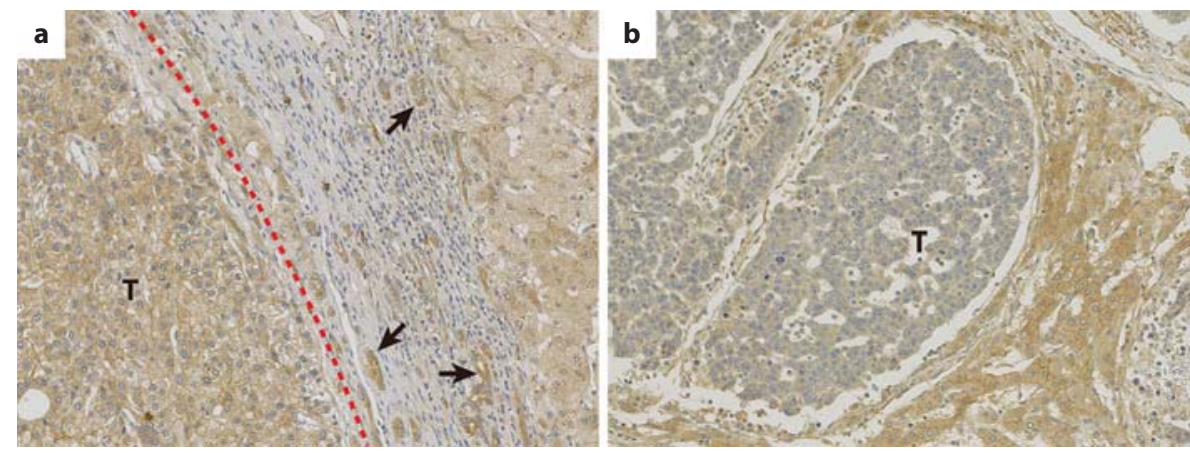

these genes are, however, rare in HCC. Although reduced TGFBR2 expression, which results in suppression of TGF- $\beta$-induced growth arrest, has been found in about $25 \%$ of HCCs, TGF- $\beta$ seems to be a tumor suppressor in the majority of HCCs expressing TGFBR2.

TGF- $\beta$ inhibits cell proliferation, but it also promotes tumor cell invasion by inducing epithelial-mesenchymal transition (EMT) [18]. Coulouarn et al. [19] described the molecular classification of HCC based on the clinical significance of the genes embedded in the TGF- $\beta$ expression signature. In their study, they examined HCC cell lines using a clustering analysis of microarray data. They found that the early or late response of the cells to TGF- $\beta$ was a key factor to subclassifying HCC. Genes in the late TGF- $\beta$ signature include vimentin and Snail, which are characteristic of EMT, suggesting that TGF- $\beta$ signaling is involved in the EMT of HCC cells. In their study, the HCC cell lines, HLE and HLF, were classified into the late TGF- $\beta$ subgroup. On the other hand, HLE and HLF cells appear to be negative for TGFBR1 and have a low level of TGFBR2, and growth inhibition with TGF- $\beta$ is not observed in these cells [20]. These findings suggest that the late response to TGF- $\beta$ may be independent of the expression of TGF- $\beta$ receptors. Reduced expression of TGF- $\beta$ receptor may be a key to shift the TGF- $\beta$ expression signature from the early to the late response.

TGF- $\beta$ signaling is also involved in angiogenesis during cancer progression. Ito et al. [21] showed that plasma TGF- $\beta$ levels correlate positively with tumor vascularity. Mazzocca et al. [22] demonstrated that crosstalk between HCC and endothelial cells was blocked with LY210976, an inhibitor of TGFBR1, by suppressing angiogenesis through vascular endothelial growth factor (VEGF). VEGF is a gene involved in the late response to TGF- $\beta$ [19]. Thus, TGF- $\beta$ promotes HCC cells to secrete VEGF, which induces hypervascularization, one of the features of advanced HCC.
Whereas TGF- $\beta$ phosphorylates the C-terminal region of R-SMADs, MAPK phosphorylates the linker region of R-SMADs [23]. Mori et al. [24] showed that hepatocyte growth factor (HGF) and TGF- $\beta$ induce R-SMAD phosphorylation at linker regions by JNK, one of the mediators of MAPK pathway. The nuclear accumulation of R-SMAD with a phosphorylated linker region is involved in invasion. Coulouarn et al. [19] demonstrated that HCC cells with the late TGF- $\beta$ signature expressed genes characteristic of TGF- $\beta$-induced metastasis and EMT. These findings led to the hypothesis that the phosphorylation of $\mathrm{R}-\mathrm{SMAD}$ at the C-terminal or linker region may be reflected in the early or late gene response to TGF- $\beta$. In other words, switching the gene response to TGF- $\beta$ may be implicated in the phosphorylation status of R-SMAD.

Coulouarn et al. [19] identified that the HCC group harboring both the late TGF- $\beta$ and positive HGF/MET signature is characterized by poor survival. HGF is expressed at significant levels in HCCs, and is primarily expressed by stromal myofibroblasts [25]. Pathologically characteristic differences between early and advanced HCCs are hypervascularization and stromal formation. Since TGF- $\beta$ induces the transformation of myofibroblasts [26], HCC cells expressing TGF- $\beta$ can obtain HGF secreted by myofibroblasts surrounding the tumor. Moreover, TGF- $\beta$-induced angiogenesis may increase HGF levels in hypervascularized HCC. HGF activates JNK, which in turn phosphorylates R-SMADs at the linker region [24]. Thus, the JNK-SMAD pathway may predominate in advanced HCC.

\section{Conclusion}

Alterations of TGF- $\beta$ levels and TGF- $\beta$ signaling in multistep hepatocarcinogenesis appear very complex, but they seem to have a significant impact on the molecular 


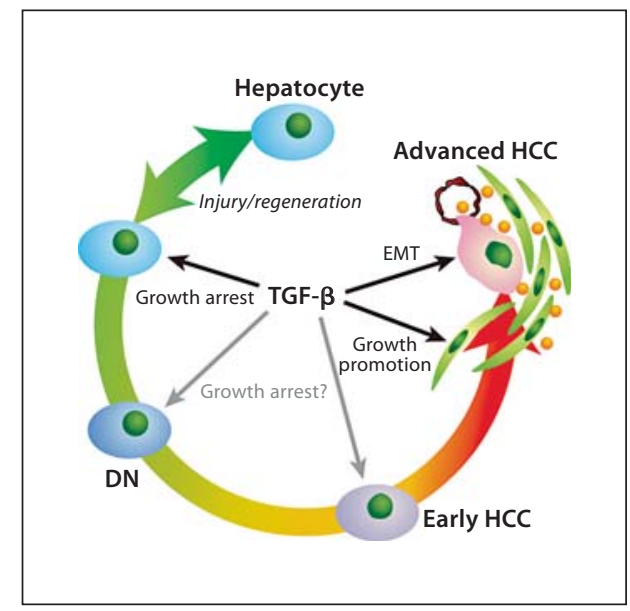

Fig. 2. Role of TGF- $\beta$ during multistep hepatocarcinogenesis. TGF- $\beta$ inhibits the proliferation of premalignant hepatocytes and early HCCs, whereas it promotes stromal formation. In HCC cells with the late response to TGF- $\beta$, TGF- $\beta$ contributes to tumor invasion through tumor-stromal interaction. pathogenesis of HCC. Figure 2 shows a scheme for the role of TGF- $\beta$ in multistep carcinogenesis. TGF- $\beta$ signaling has a suppressive role in the proliferation of premalignant hepatocytes and possibly also early HCC cells. In advanced HCCs, TGF- $\beta$ is involved in the formation of tumor stroma, including myofibroblasts and blood vessels. The stroma provides the microenvironment, including HGF, favorable for tumor cells. In advanced HCC, with such a microenvironment, the early response to TGF- $\beta$ may shift to the late response, and TGF- $\beta$ signaling cannot function as a tumor suppressor any longer. Reduced TGFBR2 expression in HCC cells may contribute to suppressing the early TGF- $\beta$ response, and enhancing the late response.

\section{Disclosure Statement}

The are no conflicts of interest to declare.

\section{References}

1 World Health Organization (WHO). Cancer. Fact Sheet No. 297. http://www.who.int/mediacentre/factsheets/fs297/en/index.html (2009).

$\checkmark 2$ Yuen MF, Hou JL, Chutaputti A: Asia-Pacific Working Party on Prevention of Hepatocellular Carcinoma: Hepatocellular carcinoma in the Asia-Pacific region. J Gastroenterol Hepatol 2009;24:346-353.

- 3 Oda T, Tsuda H, Sakamoto M, Hirohashi S: Different mutations of the $p 53$ gene in nodule-in-nodule hepatocellular carcinoma as a evidence for multistage progression. Cancer Lett 1994;83:197-200.

-4 Qin L, Tang Z, Ma Z, Wu Z, Zhou X, Ye Q, Ji Y, Huang L, Jia H, Sun H, Wang L: p53 immunohistochemical scoring: an independent prognostic marker for patients after hepatocellular carcinoma resection. World Gastroenterol 2002;8:459-463.

5 Hui AM, Sakamoto M, Kanai Y, Ino Y, Gotoh M, Yokota J, Hirohashi S: Inactivation of p16INK4 in hepatocellular carcinoma. Hepatology 1996;24:575-579.

6 Nakanishi K, Sakamoto M, Yamasaki S, Todo S, Hirohashi S: Akt phosphorylation is a risk factor for early disease recurrence and poor prognosis in hepatocellular carcinoma. Cancer 2005; 103:307-312.

-7 Chuma M, Sakamoto M, Yamazaki K, Ohta T, Ohki M, Asaka M, Hirohashi S: Expression profiling in multistage hepatocarcinogenesis: identification of HSP70 as a molecular marker of early hepatocellular carcinoma. Hepatology 2003;37:198-207.
8 Shibata R, Mori T, Du W, Chuma M, Gotoh M, Shimazu M, Ueda M, Hirohashi S, Sakamoto M: Overexpression of cyclase-associated protein 2 in multistage hepatocarcinogenesis. Clin Cancer Res 2006;12:5363-5368.

-9 Shirai Y, Kawata S, Tamura S, Ito N, Tsushima H, Takaishi K, Kiso S, Matsuzawa Y: Plasma transforming growth factor- $\beta_{1}$ in patients with hepatocellular carcinoma. Comparison with chronic liver diseases. Cancer 1994;73:2275-2279.

$>10$ Bissell DM, Roulot D, George J: Transforming growth factor- $\beta$ and the liver. Hepatology 2001;34:859-867.

11 Okumoto K, Hattori E, Tamura K, Kiso S, Watanabe H, Saito K, Saito T, Togashi H, Kawata S: Possible contribution of circulating transforming growth factor- $\beta_{1}$ to immunity and prognosis in unresectable hepatocellular carcinoma. Liver Int 2004;24:21-28.

12 Teicher BA: Malignant cells, directors of the malignant process: role of transforming growth factor- $\beta$. Cancer Metastasis Rev 2001;20:133-143.

13 Mamiya T, Yamazaki K, Masugi Y, Mori T, Effendi K, Du W, Hibi T, Tanabe M, Ueda M, Takayama T, Sakamoto M: Reduced transforming growth factor- $\beta$ receptor II expression in hepatocellular carcinoma correlates with intrahepatic metastasis. Lab Invest 2010;90:1339-1345.

14 Heldin CH, Miyazono K, ten Dijke P: TGF- $\beta$ signalling from cell membrane to nucleus through SMAD proteins. Nature 1997;390: 465-471.
15 Dooley S, Weng H, Mertens PR: Hypotheses on the role of transforming growth factor- $\beta$ in the onset and progression of hepatocellular carcinoma. Dig Dis 2009;27:93-101.

16 Hahn SA, Schutte M, Hoque AT, Moskaluk CA, da Costa LT, Rozenblum E, Weinstein CL, Fischer A, Yeo CJ, Hruban RH, Kern SE: DPC4, a candidate tumor suppressor gene at human chromosome 18q21.1. Science 1996; 271:350-353

17 Markowitz S, Wang J, Myeroff L, Parsons R, Sun L, Lutterbaugh J, Fan RS, Zborowska E, Kinzler KW, Vogelstein B: Inactivation of the type II TGF- $\beta$ receptor in colon cancer cells with microsatellite instability. Science 1995;268:1336-1338.

18 Thiery JP, Sleeman JP: Complex networks orchestrate epithelial-mesenchymal transitions. Nat Rev Mol Cell Biol 2006;7:131-142.

19 Coulouarn C, Factor VM, Thorgeirsson SS: Transforming growth factor- $\beta$ gene expression signature in mouse hepatocytes predicts clinical outcome in human cancer. Hepatology 2008;47:2059-2067.

20 Damdinsuren B, Nagano H, Kondo M, Natsag J, Hanada H, Nakamura M, Wada $H$, Kato H, Marubashi S, Miyamoto A, Takeda Y, Umeshita K, Dono K, Monden M: TGF$\beta_{1}$-induced cell growth arrest and partial differentiation is related to the suppression of Id1 in human hepatoma cells. Oncol Rep 2006;15:401-408. 
21 Ito N, Kawata S, Tamura S, Shirai Y, Kiso S, Tsushima H, Matsuzawa Y: Positive correlation of plasma transforming growth factor$\beta_{1}$ levels with tumor vascularity in hepatocellular carcinoma. Cancer Lett 1995;89:4548.

-22 Mazzocca A, Fransvea E, Lavezzari G, Antonaci S, Giannelli G: Inhibition of transforming growth factor- $\beta$ receptor I kinase blocks hepatocellular carcinoma growth through neoangiogenesis regulation. Hepatology 2009;50:1140-1051.
23 Kretzschmar M, Liu F, Hata A, Doody J, Massagué J: The TGF- $\beta$ family mediator Smad1 is phosphorylated directly and activated functionally by the BMP receptor kinase. Genes Dev 1997;11:984-995.

24 Mori S, Matsuzaki K, Yoshida K, Furukawa F, Tahashi Y, Yamagata H, Sekimoto G, Seki T, Matsui H, Nishizawa M, Fujisawa J, Okazaki K: TGF- $\beta$ and HGF transmit the signals through JNK-dependent Smad2/3 phosphorylation at the linker regions. Oncogene 2004;23:7416-7429.
25 Guirouilh J, Le Bail B, Boussarie L, Balabaud C, Bioulac-Sage P, Desmoulière A, Schuppan D, Rosenbaum J: Expression of hepatocyte growth factor in human hepatocellular carcinoma. J Hepatol 2001;34:78-83.

26 Dooley S, Delvoux B, Lahme B, MangasserStephan K, Gressner AM: Modulation of transforming growth factor- $\beta$ response and signaling during transdifferentiation of rat hepatic stellate cells to myofibroblasts. Hepatology 2000;31:1094-1106. 